\title{
Capillary electrophoresis for the analysis of short-chain organic acids in coffee
}

\author{
Verónica Galli, Coral Barbas* \\ Facultad de CC. Experimentales y de la Salud, Universidad San Pablo-CEU, Urbanización Montepríncipe, \\ Boadilla del Monte, 28668 Madrid, Spain
}

\begin{abstract}
A simple and rapid capillary electrophoresis method for low-molecular mass carboxylic acids measurement in coffee has been optimised and validated. Regarding separation conditions, phosphate concentration in the background electrolyte, surfactant type [cetyltrimethylammonium bromide (CTAB), tetradecyltri methylammonium bromide (TTAB) and hexadimethrine bromide (HDB)], percentages of organic modifier and $\mathrm{pH}$ were assayed. The best conditions were: $500 \mathrm{mM}$ phosphate buffer at $\mathrm{pH} 6.25$ with CTAB $0.5 \mathrm{mM}$. The separation was carried out with an uncoated fused-silica capillary $(57 \mathrm{~cm} \times 50 \mu \mathrm{m}$ i.d.) which was operated at $-10 \mathrm{kV}$ potential. Detection was performed at $200 \mathrm{~nm}$. In such conditions 17 short-chain organic acids: oxalic, formic, fumaric, mesaconic, succinic, maleic, malic, isocitric, citric, acetic, citraconic, glycolic, propionic, lactic, furanoic, pyroglutamic, quinic acids plus nitrate were separated, identified and measured. Validation parameters of the method allow us to consider it lineal, accurate and precise and, therefore, reliable for its employment in food composition studies or for quality control. Results in coffees with different industrial treatment allow the detection of important differences in the organic acid profile. (C) 2003 Elsevier B.V. All rights reserved.
\end{abstract}

Keywords: Coffee; Food analysis; Beverages; Organic acids

\section{Introduction}

A primary coffee taste sensation is acidity. Lowmolecular-mass (low- $M_{\mathrm{r}}$ ) organic acids contribute to both taste and flavour, as most of them are volatile. The acids found in roasted coffee may be classified into four groups: aliphatic, chlorogenic, alicyclic and phenolic acids [1]. The acidity or sourness of coffee brews has (together with aroma and bitterness) always been recognised as an important attribute of their sensory quality. In general, the acids present in coffee are responsible for about $11 \%$ of the green coffee beans' mass and for $6 \%$ of roasted coffee beans' mass [2]. Especially in high-quality beans (arabica), roasted to light or medium roast degrees, a major taste is sourness [3].

Organic acids in green and roasted coffee have been determined by several procedures, mainly GC and HPLC. A comprehensive review of the work carried out on the subject has been recently given by Balzer [4]. Even more recently, Jham et al. have compared the performance of GC

\footnotetext{
* Corresponding author. Fax: +34-91-35-10475.

E-mail address: cbarbas@ceu.es (C. Barbas).
}

and HPLC for the quantification of organic acids in coffee [5]. They concluded that the GC method was unsuitable for studies including a large number of samples, since it is very tedious, while an HPLC method which employed an ion-exchange column and a flow gradient with UV detection at $210 \mathrm{~nm}$ was found to be much simpler, but in real samples only four acids were detectable (citric, quinic, malic and fumaric acids). Trying to respond to the lack of rapid and simple analytical methods for short-chain organic acids in complex matrices, Weers et al. developed a method with a technique very well suited for this purpose: capillary electrophoresis (CE) [6]. They employed indirect detection and a surfactant to reverse the electroosmotic flow.

$\mathrm{CE}$ has proved to be a good choice for the investigation of low-molecular-mass organic acids in complex aqueous samples [7,8] with high efficiency and minimum sample pre-treatment. Our work group has been working for a long time with short-chain organic acids in matrices as different and complex as natural latex serum $[9,10]$, urine [7,11,12], wine [13] or orange juices [8]. A comprehensive survey of capillary electrophoresis methods developed for the measurement of short-chain organic acids and inorganic anions in a wide variety of matrices has been recently published 
[14]. In our experience direct UV detection provides higher sensitivity and precision in real samples and the ability to detect UV absorbing organic acids, such as oxalic, fumaric or pyroglutamic, which cannot be detected with the indirect system [13]. Other authors have similar results [15].

The objectives of the present work were the identification of small carboxylic acids in coffee extracts, optimisation of the sample preparation and separation conditions by reversed polarity CE with direct UV detection, validation of the method and application to several coffee extracts.

\section{Materials and methods}

\subsection{Instrumentation}

The separation was performed on a capillary electrophoresis MDQ (Beckman) with UV detection at $200 \mathrm{~nm}$. The injection was by pressure $(0.035 \mathrm{bar})$ for $5 \mathrm{~s}$. The separation was carried out with an uncoated fused-silica capillary $(57 \mathrm{~cm} \times 50 \mu \mathrm{m}$ i.d. $)$ and was operated at $-10 \mathrm{kV}$ potential. Temperature was maintained at $25^{\circ} \mathrm{C}$. The background electrolyte was prepared with $0.5 \mathrm{M} \mathrm{H}_{3} \mathrm{PO}_{4}, 0.5 \mathrm{mM} \mathrm{CTAB}$, as cationic surfactant to decrease electroosmotic flow, and $\mathrm{pH}$ adjusted by adding $\mathrm{NaOH}$ to 6.25 . The current generated in such conditions was $115 \mu \mathrm{A}$.

The capillary was flushed between runs with $0.1 \mathrm{M} \mathrm{NaOH}$ for $3 \mathrm{~min}, \mathrm{H}_{2} \mathrm{O}$ for $3 \mathrm{~min}$ and the background electrolyte for $5 \mathrm{~min}$.

Several parameters were studied during the optimization of the method, such as $\mathrm{pH}$ and concentration of the background electrolyte (BGE) ranging from 5.5 to 6.5 and from 400 to $600 \mathrm{mM}$, respectively with small increments. Temperature from 20 to $30^{\circ} \mathrm{C}$, the presence of methanol and acetonitrile as organic modifiers, the addition of $\mathrm{CaCl}_{2}$ as complexing agent and the employment of different surfactants [cetyltrimethylammonium bromide (CTAB), tetradecyltrimethylammonium bromide (TTAB) and hexadimethrine bromdie (HDB)] were also tested.

\subsection{Chemicals}

Standards were obtained from Sigma (St. Louis, MO, USA). Phosphoric acid 85\% was from Merck (Darmstadt, Germany), sodium hydroxide from Panreac (Madrid, Spain) and organic solvents from Scharlau (Barcelona, Spain).

\subsection{Samples}

Samples of coffee with different origins and treatment were obtained from different brands available on the market. The extraction process consisted in mechanical shaking of $1 \mathrm{~g}$ of coffee with particle size under $0.4 \mathrm{~mm}$ with $10 \mathrm{ml}$ of purified water for $10 \mathrm{~min}$. Then, samples were centrifuged at $2700 \mathrm{rpm}$ for $5 \mathrm{~min}$. All sample solutions were filtered through $0.22 \mu \mathrm{m}$ nylon filters prior to analysis.
During the optimization different extraction methods were tested related to the coffee/water ratio as well as mechanical extraction, and focussed and bath sonication.

\subsection{Validation}

Individual stock solutions of each organic acid $20-130 \mathrm{mM}$ in purified water were prepared and stored at $-20^{\circ} \mathrm{C}$ with this concentration. On the day of the analysis they were adequately diluted.

Linearity of response for standards was tested assaying by triplicate using six levels of concentrations, ranging from 0.125 to $0.5 \mathrm{mM}$ for nitrate, citraconic and furanoic; from 0.25 to $1 \mathrm{mM}$ for oxalic; from 2 to $8 \mathrm{mM}$ for formic; from 0.025 to $0.1 \mathrm{mM}$ for maleic; from 0.06 to $0.24 \mathrm{mM}$ for fumaric and mesaconic; from 0.5 to $2 \mathrm{mM}$ for succinic and lactic; from 0.75 to $3 \mathrm{mM}$ for malic and isocitric; from 1 to $4 \mathrm{mM}$ for citric, propionic and quinic; from 1.5 to $6 \mathrm{mM}$ for acetic and glycolic and from 0.05 to $1 \mathrm{mM}$ for pyroglutamic acids.

Recovery was estimated comparing the values obtained in the linearity test for spiked samples with the corresponding standards linearity, taking into account the coffee concentrations, which had been previously quantified.

Within-day precision was tested both to check the constancy of instrumental response to a given analyte and the repetitiveness of concentrations. For this purpose, the assay was performed with ten solutions of standards and 10 of samples, in the medium concentration of the calibration curve for all the compounds.

Limits of detection (LODs) were calculated following IUPAC recommendations $\left[\left(a+3 S_{B}\right) / b\right]$ where $a$ is the intercept, $b$ is the slope and $S_{\mathrm{B}}$ is the standard deviation of the blank, for chromatographic methods [16] by extrapolating to zero concentration the standard deviation of the last three points of linearity and interpolating this value in the corresponding equation.

\section{Results and discussion}

\subsection{Extraction of samples}

Concerning extraction, three levels of particle sizes were tested: under $0.2 \mathrm{~mm}$, between 0.4 and $0.2 \mathrm{~mm}$ and over $0.4 \mathrm{~mm}$. Three replicates of each fraction were analysed and data were statistically tested with one-way analysis of variance (ANOVA) $(P<0.05)$. It was observed that particle size presented little influence on extraction once it was under $0.4 \mathrm{~mm}$ and that was the size established for the samples. Focussed sonication, bath sonication and mechanical shaking were also compared by their extraction ability finding no difference in the results and therefore, mechanical shaking was selected. Coffee/water ratios ranging from $0.5 \mathrm{~g} / 10 \mathrm{ml}$ to $5 \mathrm{~g} / 10 \mathrm{ml}$ were also tested with different injection times in capillary electrophoresis to obtain higher efficiency not 
Table 1

Main validation parameters for linearity and accuracy

\begin{tabular}{|c|c|c|c|c|c|c|c|c|c|c|}
\hline & \multicolumn{8}{|l|}{ Linearity } & \multicolumn{2}{|c|}{$\begin{array}{l}\text { Accuracy: recovery } \\
\pm \text { R.S.D. }(\%)\end{array}$} \\
\hline & \multicolumn{4}{|l|}{ Standards } & \multicolumn{4}{|l|}{ Sample } & \multirow[t]{2}{*}{ Standards } & \multirow[t]{2}{*}{ Samples } \\
\hline & Range $(\mathrm{mM})$ & $a^{1} \pm \mathrm{LC}$ & $b^{2} \pm \mathrm{LC}$ & $M_{\mathrm{r}}$ & Range (mM) & $a^{1} \pm \mathrm{LC}$ & $b^{2} \pm \mathrm{LC}$ & $M_{\mathrm{r}}$ & & \\
\hline Nitrate & $0.125-0.500$ & $-0.22 \pm 0.07$ & $4.6 \pm 0.2$ & 0.997 & $0.123-0.499$ & $-0.25 \pm 0.07$ & $4.8 \pm 0.2$ & 0.996 & $100 \pm 4$ & $100 \pm 3$ \\
\hline Oxalate & $0.250-1.000$ & $-0.03 \pm 0.04$ & $1.59 \pm 0.05$ & 0.998 & $0.161-0.907$ & $-0.04 \pm 0.03$ & $1.69 \pm 0.03$ & 0.999 & $100 \pm 3$ & $100 \pm 3$ \\
\hline Formate & $2.000-8.000$ & $0.01 \pm 0.02$ & $0.073 \pm 0.004$ & 0.995 & $1.833-7.847$ & $-0.01 \pm 0.02$ & $0.079 \pm 0.003$ & 0.997 & $100 \pm 4$ & $99 \pm 4$ \\
\hline Fumarate & $0.060-0.240$ & $-0.02 \pm 0.03$ & $8.04 \pm 0.02$ & 0.999 & $0.070-0.250$ & $-0.08 \pm 0.03$ & $8.8 \pm 0.2$ & 0.999 & $100 \pm 2$ & $100 \pm 2$ \\
\hline Mesaconate & $0.060-0.240$ & $0.04 \pm 0.03$ & $6.3 \pm 0.2$ & 0.998 & $0.038-0.219$ & $0.009 \pm 0.02$ & $7.3 \pm 0.2$ & 0.999 & $100 \pm 3$ & $100 \pm 2$ \\
\hline Succinate & $0.500-2.000$ & $-0.01 \pm 0.02$ & $0.45 \pm 0.02$ & 0.998 & $0.070-1.120$ & $-0.03 \pm 0.02$ & $0.63 \pm 0.03$ & 0.997 & $100 \pm 3$ & $98 \pm 7$ \\
\hline Maleate & $0.025-0.100$ & $0.05 \pm 0.1$ & $4.8 \pm 1.5$ & 0.885 & $0.015-0.090$ & $0.02 \pm 0.1$ & $4.31 \pm 1.8$ & 0.778 & $99 \pm 22$ & $92 \pm 40$ \\
\hline Malate & $0.750-3.000$ & $0.22 \pm 0.15$ & $0.42 \pm 0.08$ & 0.958 & $0.550-2.800$ & $-0.02 \pm 0.12$ & $0.54 \pm 0.07$ & 0.973 & $99 \pm 12$ & $101 \pm 11$ \\
\hline Isocitrate & $0.750-3.000$ & $-0.1 \pm 0.1$ & $0.80 \pm 0.06$ & 0.993 & $0.559-2.810$ & $-0.07 \pm 0.09$ & $0.76 \pm 0.05$ & 0.993 & $101 \pm 5$ & $100 \pm 6$ \\
\hline Citrate & $1.000-4.000$ & $-0.04 \pm 0.04$ & $0.92 \pm 0.01$ & 0.999 & $1.612-4.585$ & $-0.14 \pm 0.05$ & $0.98 \pm 0.02$ & 0.999 & $100 \pm 1$ & $100 \pm 1$ \\
\hline Acetate & $1.500-6.000$ & $0.006 \pm 0.025$ & $0.191 \pm 0.006$ & 0.998 & $2.643-7.153$ & $-0.04 \pm 0.04$ & $0.203 \pm 0.007$ & 0.998 & $100 \pm 2$ & $100 \pm 2$ \\
\hline Citraconate & $0.125-0.500$ & $-0.34 \pm 0.07$ & $6.6 \pm 0.2$ & 0.999 & $0.141-0.517$ & $-0.35 \pm 0.06$ & $9.7 \pm 0.2$ & 0.999 & $100 \pm 2$ & $100 \pm 2$ \\
\hline Glycolate & $1.500-6.000$ & $-0.002 \pm 0.03$ & $0.198 \pm 0.008$ & 0.998 & $0.565-5.060$ & $-0.009 \pm 0.02$ & $0.221 \pm 0.006$ & 0.998 & $100 \pm 4$ & $101 \pm 6$ \\
\hline Propionate & $1.000-4.000$ & $0.26 \pm 0.2$ & $0.26 \pm 0.07$ & 0.913 & $0.422-3.415$ & $-0.05 \pm 0.05$ & $0.33 \pm 0.02$ & 0.990 & $96 \pm 26$ & $99 \pm 8$ \\
\hline Lactate & $0.500-2.000$ & $0.02 \pm 0.02$ & $0.32 \pm 0.01$ & 0.998 & $0.196-1.699$ & $0.004 \pm 0.06$ & $0.37 \pm 0.05$ & 0.963 & $100 \pm 3$ & $100 \pm 17$ \\
\hline Furanoate & $0.125-0.500$ & $-0.07 \pm 0.10$ & $3.6 \pm 0.3$ & 0.991 & $0.073-0.449$ & $-0.007 \pm 0.03$ & $3.6 \pm 0.1$ & 0.999 & $101 \pm 8$ & $100 \pm 2$ \\
\hline Pyroglutamate & $0.050-1.000$ & $-0.04 \pm 0.06$ & $4.7 \pm 0.1$ & 0.999 & $0.418-1.165$ & $-0.2 \pm 0.2$ & $5.1 \pm 0.3$ & 0.995 & $101 \pm 4$ & $100 \pm 4$ \\
\hline Quinate & $1.000-4.000$ & $-0.001 \pm 0.02$ & $0.569 \pm 0.009$ & 0.996 & $2.984-5.998$ & $-0.3 \pm 0.2$ & $0.60 \pm 0.04$ & 0.994 & $100 \pm 2$ & $99 \pm 3$ \\
\hline
\end{tabular}

${ }^{1}$ Intercept.

2 Slope.

only with extraction but also with the separation technique. The best option was $1 \mathrm{~g}$ of coffee $/ 10 \mathrm{ml}$ purified water.

\subsection{Optimization of $B G E$}

The optimization strategy started with our experience on short-chain organic acid analysis in different matrices quoted previously and it was addressed towards small variations to obtain maximum resolution between the acids present in this type of samples and the possible interferences.

With this objective $\mathrm{pH}$ was varied from 5.5 to 6.5 with 0.25 increments and $\mathrm{pH} 6.25$ gave the best results. Phosphate concentration was tested from 400 to $600 \mathrm{mM}$. These values are high for usual practice in capillary electrophoresis, but currents are maintained under acceptable limits and it is necessary to give sufficient resolution of analytes while

Table 2

Main validation parameters for precision

\begin{tabular}{|c|c|c|c|c|c|c|c|c|c|c|}
\hline & \multirow{2}{*}{\multicolumn{2}{|c|}{$\begin{array}{l}\text { Instumental precision } \\
\text { Standards }\end{array}$}} & \multicolumn{6}{|c|}{ Sample precision } & \multicolumn{2}{|c|}{ LOD (mM) } \\
\hline & & & \multicolumn{2}{|l|}{ Day 1} & \multicolumn{2}{|l|}{ Day 2} & \multicolumn{2}{|l|}{ Intermediate } & \multirow[t]{2}{*}{ Standards } & \multirow[t]{2}{*}{ Sample } \\
\hline & Media (mM) & R.S.D. (\%) & Media (mM) & R.S.D. (\%) & Media $(\mathrm{mM})$ & R.S.D. (\%) & Media (mM) & R.S.D. (\%) & & \\
\hline Nitrate & 0.250 & 1.9 & 0.151 & 3.2 & 0.143 & 6.4 & 0.147 & 5.4 & 0.10 & 0.06 \\
\hline Oxalate & 0.500 & 5.0 & 0.247 & 3.6 & 0.245 & 6.3 & 0.246 & 5.0 & 0.71 & 0.44 \\
\hline Formate & 4.000 & 6.2 & 3.382 & 4.0 & 3.482 & 5.4 & 3.432 & 4.8 & 107.26 & 156.01 \\
\hline Fumarate & 0.120 & 1.7 & 0.136 & 2.0 & 0.131 & 2.6 & 0.134 & 2.8 & 0.02 & 0.01 \\
\hline Mesaconate & 0.120 & 1.3 & 0.082 & 2.0 & 0.077 & 3.4 & 0.080 & 4.2 & 0.04 & 0.01 \\
\hline Succinate & 0.756 & 2.5 & 0.138 & 28.0 & 0.129 & 29.3 & 0.133 & 28.4 & 1.28 & 1.21 \\
\hline Maleate & 0.050 & 22.8 & 0.055 & 11.0 & 0.058 & 5.7 & 0.057 & 8.9 & 0.004 & 0.003 \\
\hline Malate & 1.498 & 7.9 & 0.940 & 11.0 & 0.859 & 11.0 & 0.904 & 11.8 & 1.45 & 1.49 \\
\hline Isocitrate & 1.499 & 2.9 & 0.941 & 7.0 & 0.913 & 8.6 & 0.927 & 8.0 & 1.12 & 1.11 \\
\hline Citrate & 1.999 & 1.5 & 2.957 & 2.0 & 2.843 & 3.8 & 2.900 & 3.6 & 1.26 & 0.41 \\
\hline Acetate & 2.989 & 2.5 & 5.077 & 2.0 & 5.050 & 9.1 & 5.063 & 6.4 & 5.00 & 17.59 \\
\hline Citraconate & 0.250 & 2.3 & 0.193 & 3.0 & 0.185 & 2.0 & 0.188 & 3.0 & 0.02 & 0.03 \\
\hline Glycolate & 3.004 & 1.9 & 1.114 & 7.0 & 1.312 & 7.3 & 1.208 & 10.9 & 32.16 & 3.58 \\
\hline Propionate & 1.995 & 9.6 & 0.333 & 19.0 & - & - & - & - & 6.56 & 0.15 \\
\hline Lactate & 0.995 & 3.2 & 0.398 & 10.0 & 0.348 & 8.2 & 0.369 & 11.0 & 3.83 & 2.01 \\
\hline Furanoate & 0.250 & 2.8 & 0.113 & 9.0 & 0.120 & 6.8 & 0.117 & 7.9 & 0.09 & 0.11 \\
\hline Pyroglutamate & 0.501 & 1.4 & 0.731 & 3.0 & 0.750 & 2.9 & 0.740 & 3.0 & 0.23 & 0.12 \\
\hline Quinate & 1.997 & 2.0 & 5.499 & 3.0 & 5.451 & 3.4 & 5.475 & 3.3 & 10.67 & 7.66 \\
\hline
\end{tabular}




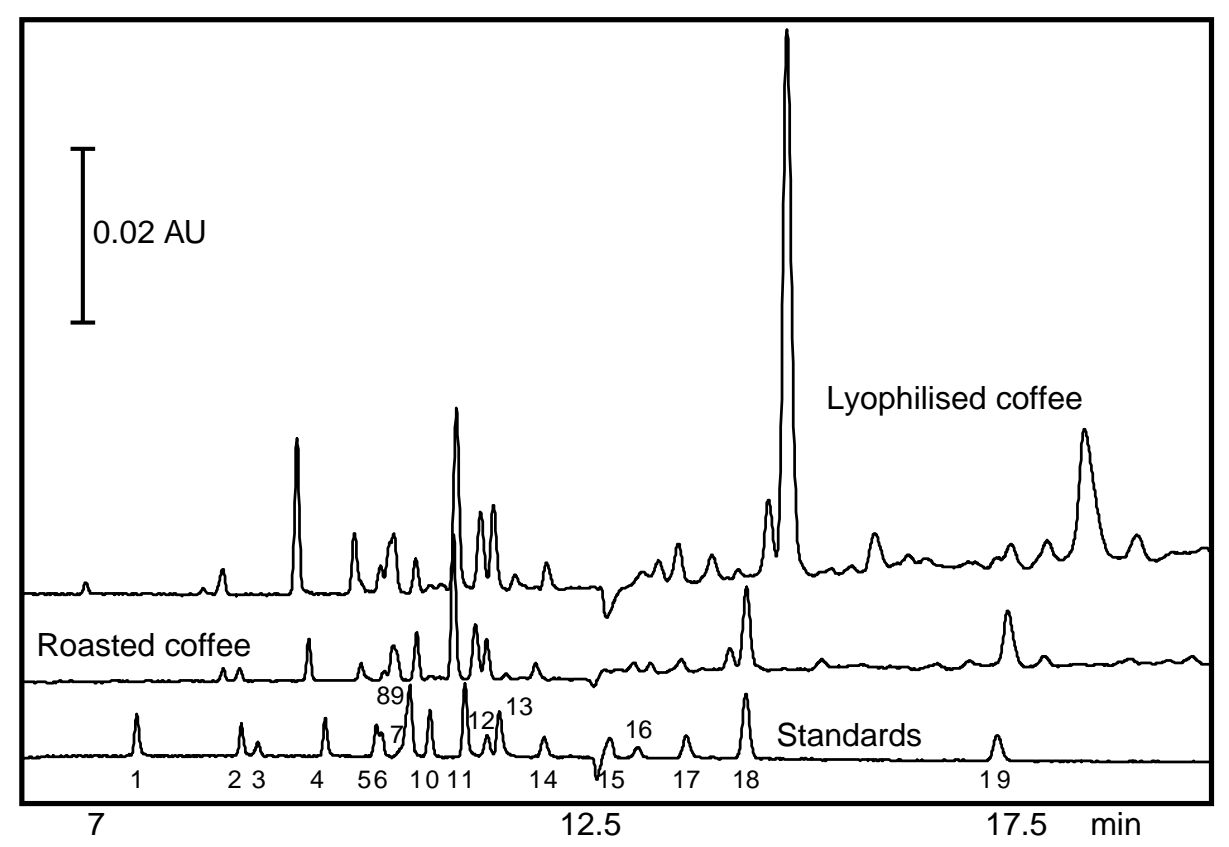

Fig. 1. Electropherogram of a standard mixture and sample of lyophilised and roasted Colombian coffee. Buffer, $500 \mathrm{mM} \mathrm{H}_{3} \mathrm{PO}_{4}, \mathrm{CTAB}_{0.5 \mathrm{mM}} \mathrm{pH}$ 6.25; capillary, $57 \mathrm{~cm} \times 50 \mu \mathrm{m}$ i.d. uncoated fused silica; voltage, $-10 \mathrm{kV}$; current, $115 \mu \mathrm{A}$; injection for $5 \mathrm{~s}$; detection wavelength, $200 \mathrm{~nm}$; concentration each peak: (1) $0.25 \mathrm{mM}$ nitrate; (2) $0.5 \mathrm{mM}$ oxalate; (3) $4 \mathrm{mM}$ formate; (4) $0.12 \mathrm{mM}$ fumarate; (5) $0.12 \mathrm{mM}$ mesaconitate; (6) $1.0 \mathrm{mM}$ succinate; (7) $0.05 \mathrm{mM}$ maleate; (8) $1.5 \mathrm{mM}$ isocitrate; (9) $1.5 \mathrm{mM}$ malate; (9) $0.05 \mathrm{mM}$ maleate; (10) $2 \mathrm{mM}$ glutarate (I.S.); (11) $2.0 \mathrm{mM}$ citrate; (12) $3.0 \mathrm{mM}$ acetate; (13) $0.25 \mathrm{mM}$ citraconitate; (14) $3.0 \mathrm{mM}$ glycolate; (15) $2.0 \mathrm{mM}$ propionate; (16) $1 \mathrm{mM}$ lactate; (17) $0.25 \mathrm{mM}$ furanoate; (18) $0.5 \mathrm{mM}$ pyroglutamate; (19) $2.0 \mathrm{mM}$ quinate.

still maintaining acceptable dispersive properties. It must be considered that to obtain maximum signal for the analytes, concentration of the extracts is high $(1 \mathrm{~g} / 10 \mathrm{ml})$.

Baseline resolution of malic, maleic and isocitric acids was the critical point in this step and several attempts were performed to obtain it: neither the change in surfactant type, nor the addition of $\mathrm{Ca}^{2+}$ ions, nor the presence of organic modifiers gave the expected results, therefore the conditions described in the Section 2 were finally accepted.

\subsection{Validation}

Prior to validation several internal standards were tested: glutamic, oxalacetic, phtalic, benzoic, suberic, gentisic and many other acids. Glutaric acid was the only compound with intermediate migration time and it did not overlap with other peaks in the electropherogram. Calculi described in the manuscript have been performed including the internal standard, but small differences were found when it was omitted (data not shown).

Once the compounds present in the sample were identified by migration time as compared with the standards and by spiking, selectivity was proved by injecting acids very close in migration time. The high efficiency obtained in capillary electrophoresis permits the clear separation of most of them. All the calculi were performed with peak areas.

Linearity has been determined by a series of three replicates of six levels of standards whose concentrations span $10-200 \%$ of the expected concentration range. As can be seen in Table 1, the linear regression equation applied to the results gave an intercept not significantly different from zero in most cases. When a significant non-zero intercept was obtained (nitrate, mesaconate and citraconate), it was mainly due to the good fit of the points to the regression line which made the limits of confidence (LCs) very narrow and there was no effect on the accuracy of the method. The slopes are different from zero in all cases and correlation coefficients are over 0.99 in all cases, except for maleic and malic acids which were not baseline resolved and propionic acid, which is very close to a system peak and its integration is difficult. Samples linearity is also adequate for the same reason, but this experiment was mainly developed to study the recoveries. All the recoveries include 100\% and R.S.D.s presented very adequate values with exception of maleic and propionic acids again. These two compounds presented high R.S.D.s for instrumental precision too, as shown in Table 2. Intra-assay precision of the method for samples gave R.S.D.s ranging $2-10 \%$ not considering succinate due to the low concentration found in samples which is under the limit of quantification and propionic acid. The latter was even lost in the second day of analysis. On two different days, R.S.D. values were very similar including the problem with the low levels of oxalate. Summarising all the values can be considered adequate for the levels of analytes and characteristics of the method, except for propionic and maleic acids which can be identified but quantification is poor.

With the final conditions described above oxalic, formic, fumaric, mesaconic, succinic, maleic, malic, isocitric, citric, 
Table 3

Results obtained for LWM organic acids with the CE method and values found in literature for these acids with different techniques and by different authors

\begin{tabular}{|c|c|c|c|c|c|c|c|}
\hline & \multicolumn{7}{|l|}{ Concentration $(\mathrm{mg} / \mathrm{g})$} \\
\hline & \multirow[t]{2}{*}{$\begin{array}{l}\text { Roasted Colombian } \\
\text { coffee by CE }\end{array}$} & \multirow[t]{2}{*}{$\begin{array}{l}\text { Lyophilised Colombian } \\
\text { coffee by CE }\end{array}$} & \multirow[t]{2}{*}{$\begin{array}{l}\text { Colombian Arabicas } \\
\text { by CE [6] }\end{array}$} & \multirow{2}{*}{$\begin{array}{l}\text { Commercial roasted } \\
\text { and ground coffee } \\
\text { samples by } \\
\text { HPLC-UV [18] }\end{array}$} & \multirow{2}{*}{$\begin{array}{l}\text { Commercial roasted } \\
\text { and ground coffee } \\
\text { samples by GC after } \\
\text { silylation }(\mathrm{mg} / \mathrm{g})[19]\end{array}$} & \multicolumn{2}{|c|}{$\begin{array}{l}\text { Commercial roasted and ground coffee samples } \\
\text { by GC/MS after silylation and pre-concentration } \\
\text { with free flow step electrophoresis }[20-22]\end{array}$} \\
\hline & & & & & & Range & Soluble \\
\hline Nitrate & n.d. & $0.079 \pm 0.007$ & & & & & \\
\hline Oxalate & $0.256 \pm 0.005$ & $0.17 \pm 0.01$ & & & & & \\
\hline Formate & $2.7 \pm 0.2$ & $8.1 \pm 0.2$ & $2.28-2.53$ & $1.8-2.5$ & 2.01 & & \\
\hline Fumarate & $0.206 \pm 0.008$ & $1.14 \pm 0.03$ & & & 0.12 & $0.086-0.108$ & 0.553 \\
\hline Mesaconate & $0.077 \pm 0.002$ & $0.41 \pm 0.01$ & & & 0.08 & $0.029-0.054$ & 0.269 \\
\hline Succinate & $0.18 \pm 0.02$ & $0.80 \pm 0.07$ & $0.25-0.36$ & $1.9-8.0$ & 0.07 & $0.053-0.067$ & 0.27 \\
\hline Maleate & $0.102 \pm 0.009$ & $0.46 \pm 0.04$ & & & 0.09 & $0.055-0.070$ & 0.286 \\
\hline Malate & $2.2 \pm 0.1$ & $5.7 \pm 0.3$ & $2.00-3.29$ & $1.0-3.9$ & 2.16 & & \\
\hline Isocitrate & $1.3 \pm 0.1$ & $18.3 \pm 0.9$ & & & & & \\
\hline Citrate & $10.1 \pm 0.3$ & $14.4 \pm 0.9$ & $6.34-11.10$ & $4.3-7.0$ & 6.72 & & \\
\hline Acetate & $7.3 \pm 0.3$ & $14.4 \pm 0.5$ & $3.76-4.98$ & $3.6-5.5$ & 5.15 & & \\
\hline Citraconate & $0.26 \pm 0.02$ & $0.82 \pm 0.07$ & & & 0.54 & $0.233-0.332$ & 0.798 \\
\hline Glycolate & $1.69 \pm 0.06$ & $4.0 \pm 0.3$ & $1.28-2.02$ & $1.7-4.9$ & 1.32 & $0.540-1.360$ & 1.892 \\
\hline Propionate & $0.06 \pm 0.02$ & n.d. & & & & & \\
\hline Lactate & $0.72 \pm 0.08$ & $2.1 \pm 0.3$ & $0.73-1.35$ & $0.0-1.8$ & 0.88 & $0.330-0.617$ & 1.443 \\
\hline Furanoate & $0.15 \pm 0.01$ & $0.50 \pm 0.01$ & & & 0.14 & $0.064-0.105$ & 0.328 \\
\hline Pyroglutamate & $0.85 \pm 0.05$ & $8.8 \pm 0.4$ & & & 0.87 & & \\
\hline Quinate & $9.4 \pm 0.5$ & $44 \pm 2$ & $8.81-9.12$ & $8.9-15.0$ & 7.93 & & \\
\hline
\end{tabular}


acetic, citraconic, glycolic, propionic, lactic, furanoic, pyroglutamic and quinic acids plus nitrate ion were identified in the electrophoretic profile. Fig. 1 shows the electropherogram of standards and two types of coffee: roasted and lyophilised Colombian coffee. Table 3 shows the values obtained for low- $M_{\mathrm{r}}$ organic acids in these samples as compared with the values obtained in literature by different authors, techniques and samples. The CE values were obtained for five replicates of each type of coffee (roasted and lyophilised) from extraction to measurement.

Among our results, pyroglutamic acid presents special interest. It is an amino acid naturally occurring in vegetables, but never described in roasted coffee; on the contrary, it is generally affirmed that no free amino acids are still present in coffee after roasting [17]. Pyroglutamate is known to have a number of remarkable cognitive enhancing effects, which could be also related to the properties of coffee traditionally associated with caffeine. Pyroglutamate is greatly increased in the lyophilised coffee and probably that increase is related to some stage of the industrial process, which ought to be considered.

\section{Conclusions}

Acidity of coffee beverages is an important feature in terms of their appreciation by the consumers and it is greatly modified not only by the type of coffee beans but also by the industrial processes. A capillary electrophoresis method has been developed that permits the direct measurement of 17 short-chain organic acids in coffee extracts. It is simple, rapid and reliable and, therefore, it is suitable to be applied in routine or studies with a high number of samples to be measured. When it was applied to commercial coffees, important differences were observed in some of these compounds due to the industrial treatment of coffee. This CE method could be a valuable tool to increase the knowledge in the area.

\section{Acknowledgements}

This study was supported by the San Pablo-CEU project 03/01.

\section{References}

[1] R.J. Clarke, Dev. Food Sci. 3B (1986) 1.

[2] H.G. Maier, in: Proceedings of the 12th ASIC Colloquium, Montreux, 1987, p. 229.

[3] M. Clifford, Tea Coofee Trade F. 8 (1989) 35.

[4] H.H. Balzer, in: R.J. Clarke, O.G. Vitzthum (Eds.), Coffee: Recent Developments, Blackwell Scientific Publications, UK, 2001, p. 18.

[5] G.N. Jham, S.A. Fernandes, C.F. Garcia, A. Arujo da Silva, Phytochem. Anal. 13 (2002) 99.

[6] M. Weers, H. Balzer, A. Bradbury, G. Vitzthum, in: Proceedings of the16th ASIC Colloquium, Kyoto, 1995, p. 218.

[7] A. García, C. Barbas, R. Aguilar, M. Castro, Clin. Chem. 44 (1998) 1905.

[8] L. Saavedra, A. García, C. Barbas, J. Chromatogr. A 881 (2000) 395.

[9] V. Galli, N. Olmo, C. Barbas, J. Chromatogr. A 894 (2000) 135.

[10] V. Galli, N. Olmo, C. Barbas, J. Chromatog. A 949 (2002) 367.

[11] C. Barbas, N. Adeva, R. Aguilar, M. Rosillo, T. Rubio, M. Castro, Clin. Chem. 44 (1998) 1340.

[12] C. Barbas, A. García, L. Miguel, C. Simó, J. Chromatogr. B 780 (2002) 73.

[13] L. Saavedra, C. Barbas, Electrophoresis 24 (2003) 2235.

[14] V. Galli, A. García, L. Saavedra, C. Barbas, Electrophoresis 24 (2003) 1951

[15] D. Volgger, A.J. Zemann, G.K. Bonn, M.J. Antal Jr., J. Chromatogr. A 758 (1997) 263.

[16] G.L. Long, J.D. Winefordner, Anal. Chem. 55 (1983) 712.

[17] S. Homma, R.J. Clarke, O.G. Vitzthum (Eds.), Coffee: Recent Developments, Blackwell Scientific Publishers, Great Britain, 2001, p. 50.

[18] G.H.D. van der Stegen, J. Duijin, in: Proceedings of the12th ASIC Colloquium, Montreux, 1987, p. 238.

[19] U.H. Engelhardt, H.G. Maier, Z. Lebensm.-Unters.-Forsch. 181 (1985) 20.

[20] F. Bähre, H.G. Maier, Fresenius J. Anal. Chem. 355 (1996) 190.

[21] F. Bähre, H.G. Maier, Dtsch. Lebensem.-Runds. 95 (1999) 399.

[22] F. Bähre, Dissertation, Technical University of Braunschweig, Germany, 1997. 